\title{
A Participação no Controle Social do SUS: concepção do Movimento dos Trabalhadores Rurais Sem Terra'
}

\section{The Landless Rural Workers' Movement and National Health System (SUS) Social Control: perspective of the National Collective of Health}

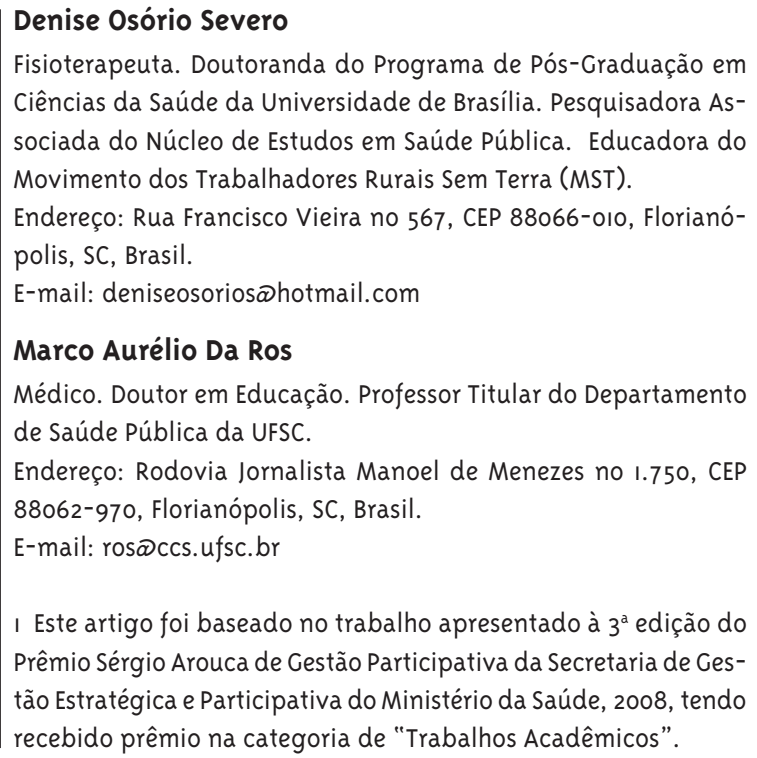

Fisioterapeuta. Doutoranda do Programa de Pós-Graduação em Ciências da Saúde da Universidade de Brasília. Pesquisadora Associada do Núcleo de Estudos em Saúde Pública. Educadora do Movimento dos Trabalhadores Rurais Sem Terra (MST). Endereço: Rua Francisco Vieira no 567, CEP 88066-010, Florianópolis, SC, Brasil.

E-mail: deniseosoriosळhotmail.com

\section{Marco Aurélio Da Ros}

Médico. Doutor em Educação. Professor Titular do Departamento de Saúde Pública da UFSC.

Endereço: Rodovia Jornalista Manoel de Menezes no 1.750, CEP 88062-970, Florianópolis, SC, Brasil.

E-mail: rosळccs.ufsc.br

I Este artigo foi baseado no trabalho apresentado à $3^{\text {a }}$ edição do Prêmio Sérgio Arouca de Gestão Participativa da Secretaria de Gestão Estratégica e Participativa do Ministério da Saúde, 2008, tendo recebido prêmio na categoria de "Trabalhos Acadêmicos".

\section{Resumo}

Trata-se de uma pesquisa exploratório-descritiva, de abordagem qualitativa, realizada com doze integrantes do Coletivo Nacional de Saúde do Movimento dos Trabalhadores Rurais Sem Terra (MST). O estudo busca identificar a concepção dos membros do Coletivo Nacional de Saúde do MST sobre a participação no controle social do SUS e discutir as estratégias adotadas nessa direção. A análise dos dados revelou que a participação nas esferas instituídas de controle social do SUS não constitui a prioridade desse Coletivo, pois fazer o controle social do SUS significa, sobretudo, fazer a luta política por meio de estratégias de ocupação, de mobilizações e de marchas. Revelou ainda uma contradição relativa à participação nos Conselhos de Saúde, visto que os entrevistados apresentam uma significativa descrença nesses espaços, embora defendam a necessidade de inserção do MST nas instâncias de controle social estabelecidas. Ademais, a concepção de Estado também emergiu como uma categoria de análise e foram identificadas duas vertentes teóricas que parecem influenciar na determinação das estratégias de controle social priorizadas. A pesquisa revela que a participação do MST no controle social do SUS ainda constitui uma questão a ser aprofundada no interior do movimento e indica que há necessidade de promoção de debates entre o conjunto do MST, a sociedade civil e a sociedade política sobre o modelo atual de controle social, com intuito de identificar e construir coletivamente mecanismos de atuação que realmente fortaleçam a participação social na gestão do SUS e contribuam para a consolidação do direito à saúde.

Palavras-chave: Participação; Controle social; MST. 


\section{Abstract}

The present study is a descriptive exploratory field research based on a qualitative approach carried out with twelve members of the National Collective of Health of the Landless Workers' Movement (MST). The objective of the study is to identify the perspective of the members of the National Collective of Health of MST about the participation of SUS social control and to discuss the strategies adopted towards them. The data analysis showed that the participation in spheres established by SUS social control does not constitute the priority of this Collective since the performance of SUS social control means to struggle politically through strategies of occupation, mobilization and marches. There is a contradiction related to the participation in Health Councils due to the fact that there is incredulity in these processes; however, there is reference to their insertion importance within these spaces. The results also demonstrate two State perspectives which seem to influence the determination of social control strategies to be preferred. The study shows that the participation of the MST in the SUS social control still needs to be discussed more thorough and points to the need of promoting debates about the current model of social control among MST, the civil society, and the political society. The debate would help to identify and build. The debate would help to identify and build a more active social participation in the SUS and help to contribute to the consolidation of Right Health.

Keywords: Participation; Social control; Landless Workers' Movement.

\section{Introdução}

[...] qualquer política só surge da luta [...] As políticas pra classe trabalhadora não vêm de graça, não vêm porque algum iluminado quis" (México)

Adentrar este artigo por meio do depoimento de um dos sujeitos da pesquisa realizada com o Movimento dos Trabalhadores Rurais Sem Terra (MST) sobre sua participação no controle social do SUS busca simbolicamente criar um espaço de reverberação das vozes que compõem esse movimento. A fala de abertura foi escolhida em virtude de seu conteúdo refletir a relevância da participação na conquista e construção de políticas públicas, evidenciando a importância dos movimentos sociais nos processos de luta por transformações das condições materiais de existência e por melhores condições de vida da população.

Com efeito, os movimentos sociais configuramse como instrumentos de enfrentamento coletivo de contradições sociais que se apresentam como obstáculos à satisfação das necessidades compartilhadas por determinados grupos (Souza, 2004). Eles refletem o modo de organização das sociedades e, como tal, têm o potencial de revelar suas contradições e criar mecanismos de luta e construção de condições favoráveis à vida.

Uma incursão no processo histórico brasileiro aponta que as lutas sociais sempre estiveram presentes, embora com variações no grau de organização e atuação. No que diz respeito à saúde, as formas de participação acompanharam as mudanças no modo de operar dos movimentos.

O Movimento dos Trabalhadores Rurais Sem Terra (MST) foi gestado nos anos 1970 e oficializado em 1984, período em que as classes populares resistiam à repressão política com respaldo de setores da Igreja Católica, desencadeando movimentos sociais como o de educação popular em saúde. O MST é considerado atualmente o maior e mais importante movimento social brasileiro e um dos principais no contexto latino-americano. Está presente em 24 Estados do Brasil (Laureano, 2007) e sua agenda política apresenta três grandes objetivos: a terra, a reforma agrária e justiça social (Caldart, 2004; Coletti, 2004; Scherer-Warren, 2002), indicando uma 
direção de luta que vai além da simples reivindicação por terra. Essa magnitude faz dele importante ator social na luta pela concretização do direito à saúde e do controle social do SUS. Além dos objetivos mencionados, cabe ressaltar que a luta do MST inclui superar o modo capitalista de produção e reorganizar a sociedade sob novas bases (Laureano, 2007).

Sua organização interna estrutura-se sob a forma de coletivos e o Setor de Saúde do movimento foi criado em 1998 (Carneiro, 2007; Daros e col., 2007). No interior do MST, o Coletivo Nacional de Saúde (CNS) representa a principal instância responsável pelo debate político nessa área. Embora a centralidade da luta do movimento não seja a saúde, as demandas sanitárias presentes em seu cotidiano exigiram a construção de respostas orientadas à concretização do direito à saúde, conduzindo à criação desse setor e evidenciando a importância da participação nessa área.

A inserção da Reforma Sanitária na Constituição de 1988 e a garantia da participação na saúde como um direito per se, corroborou o processo de mudança na conformação e atuação dos grupos organizados, pois inaugurou novos terrenos de participação dos movimentos sociais e de toda a população - instituídos posteriormente sob a forma de Conselhos e Conferências de Saúde - na tomada de decisão sobre as ações que interferem no cotidiano de suas relações sociais (Correia, 2005).

A garantia da participação da sociedade civil na elaboração, controle e fiscalização das políticas de saúde, estabelecida como um dos princípios do SUS e denominada ulteriormente de controle social do SUS, representa, de certo modo, a defesa dos direitos sociais diante da contração neoliberal do Estado no provimento de políticas públicas (Correia, 2005; Laurell, 2000; Anderson, 1995), tornando-se elemento fundamental na consolidação do direito à saúde, no exercício da cidadania e no aprofundamento da democracia participativa.

Considerando a representatividade política do MST e a importância da participação como aspecto estrutural na formação de sujeitos políticos atuantes e, consequentemente, na elevação do potencial de saúde da população, este estudo busca apreender a concepção dos integrantes do Coletivo Nacional de Saúde do MST sobre a participação no controle social do SUS e discutir as estratégias adotadas nessa direção. Com isso, pretende-se reconhecer os prováveis desafios advindos de suas concepções sobre essa forma de participação, colaborando para o debate deste tema no interior do MST e para a ampliação da participação social na saúde.

\section{Percurso Metodológico}

Trata-se de uma pesquisa exploratório-descritiva, de abordagem qualitativa, realizada com doze membros do Coletivo Nacional de Saúde do MST no segundo semestre de 2007. Este trabalho foi aprovado no Comitê de Ética da Universidade Federal de Santa Catarina, conforme protocolo 272/o7, e obedeceu à Resolução 196/96 do Conselho Nacional de Saúde. Com vistas à preservação do anonimato dos sujeitos de pesquisa, foram utilizados nomes de países latino-americanos como codinomes.

Os sujeitos da pesquisa foram indicados por um informante-chave militante do MST, tendo como critério de composição a revelação, tanto quanto possível, da diversidade de pensamentos relativa ao tema da pesquisa, presente nesse Coletivo.

A coleta de dados foi realizada por meio de entrevistas semiestruturadas e de diário de campo. As entrevistas foram feitas em Veranópolis/RS, em Brasília/DF, no Rio de Janeiro/RJ e em Florianópolis/ SC. Cabe ressaltar que, em função de a pesquisadora ser colaboradora desse Movimento no campo da educação popular em saúde, os registros em diário de campo foram realizados durante todas as vivências dela no MST durante o período da coleta.

O tratamento dos dados foi feito com base na Análise de Conteúdo de Bardin (1977). Foram realizadas leituras flutuantes com intuito de extrair os núcleos dos sentidos e desvelar as subcategorias presentes nas unidades de registro e, posteriormente, foram identificadas três categorias: concepção de controle social; a participação institucional e sua contradição e a concepção de Estado dos integrantes do Coletivo Nacional de Saúde do MST. Cada uma dessas categorias será analisada a seguir. 


\section{A Concepção de Controle Social}

Com relação à primeira categoria identificada - Concepção de Controle Social - foi possível entender que, para os entrevistados, fazer o controle social do SUS não significa necessariamente participar de esferas institucionalizadas de controle social (Conselhos e Conferências de Saúde), mas, sobretudo, fazer a luta política fora do âmbito do Estado, conforme expressa a fala a seguir:

[...] quando a gente ocupa [...] uma terra [...] isso é fazer controle social e isso éfazer saúde [...] fazer a luta social, fazer a luta de massas [...] (Peru)

A ocupação, as mobilizações e as marchas constituem as principais estratégias de luta utilizadas pelo movimento e caracterizam-se como formas de participação no controle social do SUS. Cabe esclarecer que a diferença entre o conceito de ocupação adotado pelo MST e o de invasão difundido pela mídia e defendido pela elite dominante encontra-se no campo político-ideológico e reflete o modelo de organização da sociedade que cada qual acredita e defende.

Ocupação refere-se à (re) apropriação de "espaços” e de direitos historicamente expropriados dos trabalhadores. Araújo (2007) e Caldart (2004) ponderam que a luta do MST representa, em verdade, uma luta por cidadania, pelo respeito aos direitos fundamentais do homem; direitos que, para os Sem-Terra, não são dissociados da luta pela (re) apropriação da terra. Assim, a conquista da terra simboliza a conquista da cidadania (Araújo, 2007), e a ocupação deflagra um processo de mudança na vida dos Sem-Terra, de uma situação na qual eles são representados socialmente como um povo clandestino para uma condição de um povo com destino (Arias, 2002. p.9o).

0 conceito de invasão defendido pela elite burguesa, por outro lado, fundamenta-se no princípio básico de defesa da propriedade privada - um imperativo à manutenção das relações de produção capitalistas - acima de qualquer direito fundamental.

É importante ressaltar que a ocupação defendida pelos entrevistados não se restringe à (re) apropriação da terra. Inclui também a ocupação de espaços públicos, de órgãos e de instituições relacionados de algum modo à implementação de políticas públicas.
Assim, percebe-se que as estratégias de controle social do SUS priorizadas pelo Coletivo Nacional de Saúde não diferem dos principais mecanismos adotados pelo conjunto do MST e tornaram-se hegemônicas nos movimentos sociais em toda a América Latina, no princípio do século XXI (Seoane, 2006), porém sob novas conformações. Segundo Seoane (2006), o caráter dos movimentos sociais transformou-se a partir de meados da década de 9o, passando a incluir novas camadas sociais e a defender a participação na gestão do espaço público.

Ainda que os mecanismos sustentados pelo Coletivo Nacional de Saúde do MST possam colaborar para a transformação gradual do modelo societário, no que tange às demandas específicas da saúde, esses instrumentos (ocupações, marchas e mobilizações) mostram-se frágeis, pois tendem a limitar-se ao ato reivindicatório, conduzindo ao reconhecido esvaziamento de mobilizações diante de respostas pontuais, ou à ausência de envolvimento dos sujeitos na proposição e gestão do processo das ações solicitadas.

A significativa preocupação dos entrevistados em não restringir a participação às esferas legais também indica uma participação política com tendência à oposição estatal que parece refletir uma concepção de Estado impermeável às classes dominadas, evidenciando características da participação na saúde tradicionalmente utilizadas nas décadas de 70 e 8o, cujo eixo era centrado no confronto com o Estado e na reivindicação das classes subalternas por acesso a bens e serviços sanitários (Carvalho, 1995).

Embora no interior do Coletivo Nacional de Saúde existam indícios do surgimento de novas formas de participação na gestão do SUS, orientadas à atuação em processos de elaboração de políticas de saúde, as principais estratégias adotadas não enfatizam a atuação na formulação e acompanhamento da política de saúde.

Por outro lado, essas estratégias revelam um potencial pedagógico que merece destaque. 0 engajamento na luta política, desde que acompanhado de reflexão, representa uma atitude carregada de qualidades, na medida em que a participação favorece a elevação da consciência crítica dos sujeitos ao desvelar condições de opressão na sociedade e facilitar 
a apreensão dos determinantes da produção social da saúde, contribuindo para a construção de dispositivos fundamentais ao exercício da participação no controle social do SUS. A concepção apresentada e os mecanismos priorizados conduzem à reflexão sobre a próxima categoria.

\section{A Participação Institucional e sua Contradição}

Os depoimentos revelaram uma importante contradição no discurso dos integrantes do Coletivo Nacional de Saúde do MST no que se refere à participação nos espaços instituídos de controle social do SUS: há uma significativa descrença nos Conselhos de Saúde, ao mesmo tempo em que apontam a importância da inserção do movimento nas esferas institucionais. As assertivas a seguir demonstram essa contradição:

"[Coletivo Nacional de Saúde] temos insistido que isso é importante [participação nos Conselhos] [...] nesse modelo não adianta ter camponês [...] não vai ter força de participação [...]" (Argentina)

“...] os Conselhos de Saúde éuma coisa importante, mas à medida que ele vai pra dentro do Estado [...] acaba ficando com pouca potencialidade [...] não devemo jogar força [...]" (Cuba)

Nota-se que o baixo potencial de intervenção nas decisões e a limitação inerente à relação orgânica com o Estado são elementos de destaque e parecem reforçar a descrença nas esferas estabelecidas. Ademais, a necessidade de revisão do modelo de controle social é muito relatada nas entrevistas e reflete tanto a descrença como a dissonância entre o conceito apresentado pelos integrantes do Coletivo e a concepção instituída após a Reforma Sanitária, conforme se observa na seguinte fala:

"[...] o controle social a gente precisa mudar o jeito que ele tá organizado [...]" (Guatemala)

Com efeito, a dificuldade de os usuários intervirem nos Conselhos de Saúde constitui um obstáculo bastante relatado em estudos nesse campo (Wendhausen e Cardoso, 2007; Guizardi e Pinheiro, 2006; Wendhausen e Caponi, 2002). Além disso, pesquisas indicam a existência de práticas de co- optação de lideranças em troca de favores; falta de acesso às informações; utilização de linguagem técnica como instrumento de poder e desarticulação dos conselheiros com suas bases. Tais elementos comprometem seriamente a representatividade e a legitimidade dos representantes e do próprio colegiado (Wendhausen e Cardoso, 2007; Guizardi e Pinheiro, 2006; Correia, 2005) e parecem contribuir para a descrença do CNS nessas esferas.

A prática de cooptação é motivo preocupante e de importantes debates internos. 0 receio de sofrer cooptação influencia a participação dos movimentos na gestão de espaços públicos (Scherer-Warren, 2005) e reforça a descrença dos integrantes do Coletivo Nacional de Saúde do MST na participação nos Conselhos de Saúde.

Afirmar que os problemas encontrados nos Conselhos são inerentes a eles não parece prudente, uma vez que refletem, tão somente, a cultura política autoritária brasileira, historicamente construída.

Mas é necessário ponderar que, embora os obstáculos justifiquem, parcialmente, a descrença nos Conselhos de Saúde, a não apropriação desses mecanismos pela sociedade civil organizada representa, na atual conjuntura, a renúncia ao direito de deliberar sobre as políticas de saúde no País e a transferência do poder de decisão para outros grupos.

Se considerarmos que "os homens só se apropriam do que faz sentido para suas vidas" (Gonçalves, 2004. p.264), para os entrevistados o modelo de controle social do SUS não encontra significação no imaginário social da população do campo, como pode ser observado no seguinte relato:

"[participação no Conselho de Saúde] [...] não énem que o camponês [...] não faça um esforço, mas ele não se identifica [...] é alguma coisa muito fora da realidade dele né." (México)

Essa falta de sentido encontra ressonância na ausência do sentimento de pertença nos militantes do MST ao sistema de saúde, uma vez que a criação do SUS não é percebida como uma conquista do MST, conforme nota-se na fala abaixo:

"[...] não existe [...] no Movimento Sem Terra um sentimento de pertença com relação ao SUS [...] não é uma coisa conquistada pela gente." (Nicarágua)

Embora a autonomia dos movimentos sociais 
frente ao Estado seja importante em determinados aspectos, paradoxalmente pode vir a aprofundar a abstenção do Estado no provimento de políticas públicas diante da ausência de oposição no interior da sociedade política (Estado).

\section{A Concepção de Estado}

A terceira categoria extraída dos depoimentos expõe distintas noções de Estado e influenciam a participação do MST em mecanismos de controle social estabelecidos pelo SUS. Uma entende o Estado estritamente como um instrumento de dominação da burguesia (Marx e Engels, 2006), como observado na seguinte fala: "[...] é um Estado burguês [...] independente do governo [...] vai se manter hegemônico e dominante contra outras classes dominadas [...]" (El Salvador), enquanto outra o entende como um espaço de disputa política e, como tal, passível de ser ocupado parcialmente pelas classes dominadas, identificado no seguinte depoimento: “... o Estado [...] é o campo dentro do qual a gente faz a disputa política” (Nicarágua),

A pesquisa identificou um grupo de militantes contrários à inserção do movimento no aparelho estatal ou que apresentam ressalvas no estabelecimento dessas relações, conforme pode ser observado na seguinte fala:

"[...] nós [o MST] não vamos pra dentro do Estado, mas nós precisamos mudar o Estado!" (México)

É possível inferir que os integrantes do Coletivo Nacional de Saúde identificados com a concepção leninista de guerra de movimento (Simionatto, 2004; Gruppi, 1985) não encontram sentido na participação nos mecanismos instituídos de controle social do SUS, visto que essa forma de participação na saúde não representaria uma estratégia capaz de colaborar com a transição do modelo societário.

É importante realçar que, assim como qualquer outro campo de ação e independentemente da concepção de Estado apresentada, a luta pela saúde e o exercício do controle social não representam um fim para os integrantes do Coletivo Nacional de Saúde, mas um meio, um caminho de luta por cidadania e por uma transformação ampla da sociedade, conforme podemos notar no depoimento a seguir:
"[...] o maior desafio [do MST] é recolocar o SUS e o controle do SUS [...] dentro do marco no qual ele foi pensado [...] da luta pelo socialismo [...]" (Nicarágua)

A participação do MST na elaboração e controle das políticas de saúde assume um papel estratégico na mudança estrutural, porém implica uma visão de Estado que conceba a superação do capitalismo como algo menos abrupto e mais processual.

As entrevistas evidenciam diferenças no grupo pesquisado e indicam que o conjunto do MST encontra-se em um processo de reflexão sobre sua relação com o Estado na atual conjuntura política, ainda que demonstrem uma tendência à adesão ao referencial de Gramsci quanto ao caráter processual da transformação almejada.

\section{Considerações Finais}

Com base nos depoimentos e convívio com o Movimento, foi possível entender que a participação do MST nos espaços formais de controle social do SUS é uma questão controversa e ainda em aberto entre os integrantes do Coletivo Nacional de Saúde. As categorias que emergiram do estudo descortinam distintas visões acerca desse assunto e traduzem o terreno conceitual sobre o qual transitam: o modelo de organização social e a luta por uma transformação ampla da sociedade que possa promover a real concretização dos direitos fundamentais do homem. É nessa perspectiva que o movimento pauta sua atuação e parece balizar suas estratégias de participação.

A concepção relatada de controle social se coaduna com a luta política fora do âmbito do Estado por meio de ocupações, marchas e mobilizações realizadas no cotidiano da militância no movimento e inseridas em suas lutas mais amplas. Essas estratégias de luta política alinham-se com as atuais práticas dos movimentos sociais, mas também revelam reminiscências históricas de aspectos reivindicatórios.

Os depoimentos também indicam a existência de uma contradição importante entre os integrantes do Coletivo Nacional de Saúde do MST quanto à participação institucional. A descrença nos espaços institucionais como lócus de participação social para a 
consolidação do direito à saúde e a importância da inserção do MST nesses espaços apresentaram-se polarizadas. Parte dos sujeitos desacredita na participação formal no controle social e prioriza a luta por fora, entendendo o Estado como um espaço restrito. Outra parte concebe a participação nos espaços de controle social instituídos como uma estratégia de transformação social importante.

Os resultados sinalizam a importância da ampliação do debate sobre essa polarização no interior do Coletivo Nacional de Saúde e do conjunto do MST, com vistas a encontrar o consenso necessário à elaboração de estratégias de controle social do SUS em direção à ampliação das formas de participação social na sua gestão e para a consolidação do direito à saúde.

As ocupações, as mobilizações e as marchas podem ter promovido, historicamente, avanços para o movimento no que concerne às suas grandes lutas, mas revelam-se frágeis com relação à efetivação do direito à saúde no cotidiano. Embora a Reforma Agrária represente também uma conquista sanitária, na materialidade da vida, as privações objetivas e subjetivas exigem atenção e cuidados que não podem ser postergados e não são satisfeitos somente com a conquista da terra.

Desse modo, as políticas públicas de saúde constituem demandas concretas permanentes e os serviços de saúde invariavelmente são demandados em algum momento pela população (inclusive a do MST), evidenciando a necessidade da concretização de um sistema de saúde (e o referido sistema, SUS, aí está) independentemente do modelo de Estado vigente.

Nessa perspectiva, cabe ao Coletivo Nacional de Saúde e ao conjunto do MST traçar estratégias que articulem as questões amplas com as lutas setoriais, bem como a objetividade e a subjetividade, o imediato com o mediato, pois lutar por um futuro societário pautado na justiça social, sem construir mecanismos que concretizem os direitos fundamentais no presente, significa negar o direito à saúde às bases que mantêm o movimento vivo e negar a própria história de luta dos movimentos sociais pela construção desses direitos.
É necessário promover debates entre o MST, a sociedade civil e a sociedade política sobre o modelo atual de participação no controle social do SUS, com vistas a identificar e construir (com) juntamente possíveis alternativas de atuação que fortaleçam a participação social na gestão das políticas de saúde e promovam a consolidação do SUS e do direito à saúde.

Por fim, a dissonância existente entre o conceito de participação no controle social do SUS conforme integrantes do Coletivo Nacional de Saúde do MST e o modelo garantido no plano jurídico conduz a uma nova pergunta: em que medida o desenho de controle social do SUS instituído após a Reforma Sanitária refletiu as expectativas da sociedade civil com relação à participação na saúde?

Esse questionamento incita o avanço de novas pesquisas que revelem a significação simbólica de outros movimentos sociais sobre a concepção de controle social do SUS e auxiliem a desatar os nós que se apresentam nesse campo, possibilitando tecer novas tramas que fortaleçam a rede de participação social no SUS.

\section{Referências}

ANDERSON, P. Balanço do neoliberalismo. In: SADER, E.; GENTILI, P. (Org.). Pós-neoliberalismo: as políticas sociais e o Estado democrático. Rio de Janeiro: Paz e Terra, 1995. p. o9-23.

ARAÚJO, L. E.B. O MST e a luta pela terra: a juridicização do político. In: QUEVEDO, J.; IOKOI, Z. M. G. (Orgs). Movimentos sociais na América Latina: desafios teóricos em tempos de globalização. Santa Maria: MILA/CCSH, 2007. p. 310-326.

ARIAS, P. G. La cultura: estrategias conceptuales para comprender la identidad. La diversidad, la alteridad y la diferencia. Quito: Abya-Yala, 2002. p 127.

BARDIN, L. Análise de conteúdo. Lisboa: Edições 70, 1977. p 223.

CALDART, R. S. Pedagogia do Movimento Sem Terra. São Paulo: Expressão Popular, 2004. p 439. 
CARNEIRO, F. F. A saúde no campo: das políticas oficiais à experiência do MST e de famílias de "boias frias" em Unaí, Minas Gerais, 2005. 2007. 143 p. Tese (Doutorado em Ciência Animal) - Escola de Veterinária, Universidade Federal de Minas Gerais, Belo Horizonte.

CARVALHO, A. I. Conselhos de Saúde no Brasil: participação cidadã e controle social. Rio de Janeiro: Fase/Ibam, 1995. p 135.

COLETTI, C. Avanços e impasses do MST e da luta pela terra no Brasil nos anos recentes. In: SEOANE, José (Org.). Movimientos sociales y conflicto en América Latina. Buenos Aires: Clacso, 2004. p. 279-285.

CORREIA, M. V. C. Desafios para o controle social: subsídios para capacitação de conselheiros de saúde. Rio de Janeiro: Fiocruz, 2005. p 278.

DAROS, D.; DELLAZERI, D. T.; ANDREATTA, M. O curso técnico em saúde comunitária do IEJC. Cadernos Iterra, Veranópolis ano VII, n. 13, p. 129$177,2007$.

GONÇALVES, C. W. P. A geograficidade do social: uma contribuição para o debate metodológico sobre estudos de conflito e movimentos sociais na América Latina. In: SEOANE, José (Org.). Movimientos sociales y conflicto en América Latina. Buenos Aires: Clacso, 2004. p. 279-285.

GRUPPI, L. Tudo começou com Maquiavel: as concepções de Estado em Marx, Engels, Lênin e Gramsci. Porto Alegre: L\&PM, 1985. p 93.

GUIZARDI, F. L.; PINHEIRO, R. Dilemas culturais, sociais e políticos da participação dos movimentos sociais nos Conselhos de Saúde. Ciência \& Saúde Coletiva, Rio de Janeiro, v. 11, n. 3 , p. 797-805, 2006.
LAUREANO, D. S. O MST e a Constituição: um sujeito histórico na luta pela reforma agrária no Brasil. São Paulo: Expressão Popular, 2007. p 232.

LAURELL, A. C. Globalización, políticas neoliberales y salud. In: BRICENO-LEON, R.; MINAYO, M. C. S.; COIMBRA JR., Carlos E. A. (Org.). Salud y equidad: uma mirada desde lãs ciências sociales. Rio de Janeiro: Fiocruz, 200o. p. $73-84$.

MARX, K.; ENGELS, F. O manifesto comunista. São Paulo: Paz e Terra, 2006. p 67.

SCHERER-WARREN Redes de movimentos sociais. São Paulo: Loyola, 2005. p 143.

SCHERER-WARREN. A atualidade dos movimentos sociais rurais na nova ordem mundial. In: SCHERER-WARREN, I.; FERREIRA, J. M. C. (Org.). Transformações sociais e dilemas da globalização: um diálogo Brasil/ Portugal. São Paulo: Cortez, 2002. p. 243 -257.

SEOANE, J. Movimientos sociales y recursos naturales em América Latina: resistencias al neoliberalismo, configuración de alternativas. Sociedade e Estado, Brasília, v. 21, n.1, p. 85-107, 2006.

SIMIONATTO, I. Gramsci: sua teoria, incidência no Brasil, influência no Serviço Social. 3. ed. Florianópolis: Ed. UFSC; São Paulo: Cortez Editora, 2004. p 281.

SOUZA, M. L. Desenvolvimento de comunidade e participação. 8. ed. São Paulo: Cortez, 2004. p 231.

WENDHAUSEN, A; CARDOSO, S. M. Processo decisório e Conselhos Gestores de Saúde: aproximações teóricas. Revista Brasileira de Enfermagem, Brasília, v. 6o, p. 579-84, 2007.

WENDHAUSEN, A; CAPONI, S. O diálogo e a participação em um conselho de saúde em Santa Catarina, Brasil. Cadernos de Saúde Pública, Rio de Janeiro, v. 18, n. 6, p. 1621-1628, 2002. 